
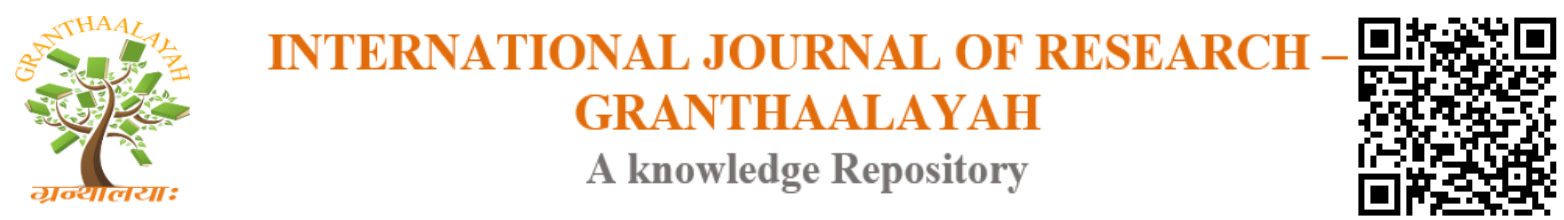

Science

\title{
PREDICTING THE COMPRESSIVE STRENGTH OF PBA - CLAY REFRACTORY BRICKS USING RESPONSE SURFACE METHOD
}

\author{
Chijioke C. ${ }^{* 1}$, Okoye P. ${ }^{2}$, Igwegbe W. E. ${ }^{3}$, Ugwuegbulam J.C. 4 \\ 1,3,4 Civil Engineering Department Federal Polytechnic Nekede Owerri \\ ${ }^{2}$ Mechanical Engineering Department Federal Polytechnic Nekede Owerri
}

\begin{abstract}
The importation of refractory materials is one of the biggest challenges industries faced in third world countries, of which Nigerian is one of them. The addition of palm bunch ash to clay in the production of clay bricks is one of the ways refractory materials are produced. The clay used here was Nsu clay. This work looked at the compressive strength of refractory bricks which is one of the properties of refractory materials. The work eliminates the traditional methods of trial and error and the rigorous mathematical analysis associated with the formation of some regression models in the prediction of some properties of refractory bricks. This was achieved by the use of Surface Response method. A regression model to predict the strength of a refractory brick was formulated, the model was found to be adequate based of the analysis of variance in which the Rsq, Rsq (adjusted) and Rsq (prediction) were found to be adequate, hence the model can be used to predict the compressive strength of refractory bricks. The optimal compressive strength was found to be $30.1513 \mathrm{KN} / \mathrm{m} 2$ at a ratio of 1:0.2570 at a water/clay ratio of 4.2590. Also, from the results it can be seen that the compressive strength of bricks decrease with increase in the percentages of palm bunch ash.
\end{abstract}

Keywords: Clay; Refractory; Brick; Compressive Strength; Palm Bunch Ash.

Cite This Article: Chijioke C., Okoye P., Igwegbe W. E., and Ugwuegbulam J.C. (2018). "PREDICTING THE COMPRESSIVE STRENGTH OF PBA - CLAY REFRACTORY BRICKS USING RESPONSE SURFACE METHOD" International Journal of Research Granthaalayah, 6(6), 472-479. https://doi.org/10.29121/granthaalayah.v6.i6.2018.1392.

\section{Introduction}

Nigeria is a third world country in dire need of cutting edge technology. The use of refractory materials such as bricks is very essential in the metallurgical industries as iron and steel industries. Almost all the metallurgical processes are heat generating system, which require refractory materials that can withstand both physical and chemical action of molten materials (Hassan et al 2014). The chief material in the production of refractory material is clay. Clay is made into refractory material by cutting molded clay into various shapes and fired in the kiln. The firing processes transform the clay into the intending use with very high compressive strength and 
excellent weathering qualities. Without refractory materials it will be very difficult to develop heavy industries and the necessary power production required for industrialization (Marwa et al 2009). Often times, admixtures such as palm bunch ash are added to raw mixes of burnt bricks in order to modify the properties or reduce the cost of the final product (Onwuka et al 2014). The addition of ash to bricks produces clay refractory. The term refractory means hard to fuse (Malu et al 2007).). Refractory materials are generally employed for the construction of furnace flues, crucible etc. used in high temperature operations because of their resistance to the corrosive action of glasses and slag present therein. The use of software to develop a model for the prediction of the compressive strength of refractory bricks is aimed at producing refractory bricks which is of optimal value, without passing through the rigorous tradition methods which is cumbersome, material wasting and time wasting.

\section{Materials and method}

\subsection{Material}

The unprocessed dry clay called Nsu clay was obtained from Isu Ihime Mbano L.G.A. of Imo State Nigeria. The palm bunch ash was obtained by burning palm bunch, a waste product from palm oil mill at Ada Palm in Ugwuta in Imo State Nigeria in the open air.

\subsection{Material Preparation}

The unprocessed clay was made into a slip by adding water to it, it later crushed, mashed, washed and stirred. It was later made to pass through a BS sieve with $300 \mu \mathrm{m}$ and filtered to remove oversized quartz, such as vegetables and other unwanted materials. The filtration process was repeated several times until all the clay powder was washed off completely. The filtered slip was allowed to settle after a little alum was added to fasten settlement process. After sedimentation the top was carefully filtered off leaving a slimy pest behind. Lastly the clay was dried in the sun and grounded with mortar and pestle to increase its compacting properties as well as aid proper blending with the ash.

The palm bunch ash was dried in the sun and was burnt completely in the open in an open drum. The ash from the process was then made to pass through BS sieve of $212 \mu \mathrm{m}$. The water used was a clean pipe borne water obtained from municipal water supply.

\subsection{Methods}

The mix proportioning refers as the mix ratios of the various components in the mixture, and was done using Surface Response Method. The total number of components are three (water, clay and palm bunch ash), so a total of twenty (20) mixes was generated by the software. The mix ratios are as seen in table 1.0. $\mathrm{X}_{1}, \mathrm{X}_{2}$ and $\mathrm{X}_{3}$ represent the mix ratio of water/clay ratio, clay/clay ratio and palm ash/clay ratio respectively. 
Table 1: Mix ratios from response surface

\begin{tabular}{|l|c|c|c|}
\hline $\mathbf{S} / \mathbf{N}$ & $\mathbf{X}_{\mathbf{1}}$ & $\mathbf{X}_{\mathbf{2}}$ & $\mathbf{X}_{\mathbf{3}}$ \\
\hline 1 & 4.05556 & 1.0000 & 0.11111 \\
\hline 2 & 4.13793 & 0.9999 & 0.149425 \\
\hline 3 & 4.18648 & 1.0000 & 0.165501 \\
\hline 4 & 4.20588 & 0.9999 & 0.176471 \\
\hline 5 & 4.22646 & 1.0000 & 0.180575 \\
\hline 6 & 4.26829 & 0.9999 & 0.219512 \\
\hline 7 & 4.27711 & 1.0000 & 0.204819 \\
\hline 8 & 4.28395 & 1.0000 & 0.234568 \\
\hline 9 & 4.28571 & 1.0000 & 0.242236 \\
\hline 10 & 4.30303 & 0.9999 & 0.212121 \\
\hline 11 & 4.31707 & 1.0000 & 0.219512 \\
\hline 12 & 4.32653 & 1.0000 & 0.224490 \\
\hline 13 & 4.35897 & 0.9999 & 0.282051 \\
\hline 14 & 4.37500 & 1.0000 & 0.250000 \\
\hline 15 & 4.43421 & 1.0000 & 0.315789 \\
\hline 16 & 4.44325 & 0.9999 & 0.310693 \\
\hline 17 & 4.45408 & 1.0000 & 0.275510 \\
\hline 18 & 4.47815 & 1.0000 & 0.285347 \\
\hline 19 & 4.48387 & 0.9999 & 0.290323 \\
\hline 20 & 4.60000 & 1.0000 & 0.333333 \\
\hline
\end{tabular}

\subsection{Production of Palm Bunch Ash - Clay Bricks}

For each mix ratios the masses were carefully measured out using weighing balance. The clay and the ash were thoroughly in the dry state and water was added, gradually the mixed raw material was thoroughly mixed together to increase the plasticity and binding properties of the clay. When the required plasticity is obtained, the raw material mixture is cast using small moulds.

\subsection{Drying Process}

The cast bricks were air dried for 72 hours after which the samples were placed in a kiln for drying. The drying was carried out in order to avoid the formation of steam within the body.

\subsection{Firing Process}

Firing was done in an electric furnace in the laboratory, the sample were fired from $0^{\circ} \mathrm{C}$ to $1200^{\circ} \mathrm{C}$ and soaked at that temperature for 1 hour. The firing schedule is as follows;

Table 2: Firing schedule

\begin{tabular}{|l|l|}
\hline Temperature & Total time taken \\
\hline $0^{\circ} \mathrm{C}$ to $900^{\circ} \mathrm{C}$ & 2 hours \\
\hline $900^{\circ} \mathrm{C}$ to $1000^{\circ} \mathrm{C}$ & 2 minutes \\
\hline $1000^{\circ} \mathrm{C}$ to $1100^{\circ} \mathrm{C}$ & 10 minutes \\
\hline $1100^{\circ} \mathrm{C}$ to $1200^{\circ} \mathrm{C}$ & \multicolumn{2}{|c|}{7 minutes then soaked. } \\
\hline
\end{tabular}




\subsection{Cold Crushing Strength}

The cold crushing strength was determined by applying uniaxial load on the specimen in cold condition. The metallurgical mounting press was used to produce this load through the hydraulic ram. The load at which the samples fracture are noted from the dial gauge. The crushing strength can be calculated from the equation;

cold crushing strength $\sigma=\frac{\text { force }(F)}{\text { cross sectional area of punch }(A)}$

cold crushing strength $\sigma=\frac{\text { load } \times 9.81}{\text { cross sectional area of punch }(A)}$

\section{Chemical Analysis of Nsu Clay}

The chemical analysis was carried at the PRODA laboratory Enugu and is as presented in table 3

\subsection{Results and Analysis}

Table 3: Chemical analysis of Nsu clay

\begin{tabular}{|l|l|}
\hline Compound & Chemical composition in percentage (\%) \\
\hline $\mathrm{CaO}$ & 4.87 \\
\hline $\mathrm{MgO}$ & 5.21 \\
\hline $\mathrm{Fe}_{2} \mathrm{O}_{3}$ & 1.76 \\
\hline $\mathrm{Na}_{2} \mathrm{O}$ & 0.92 \\
\hline $\mathrm{K} 2 \mathrm{O}$ & 1.68 \\
\hline $\mathrm{Al}_{2} \mathrm{O}_{3}$ & 24.74 \\
\hline $\mathrm{P}_{2} \mathrm{O}_{5}$ & 0.51 \\
\hline $\mathrm{TiO}_{2}$ & 0.69 \\
\hline $\mathrm{SO}_{3}$ & 1.1 \\
\hline $\mathrm{SiO}_{2}$ & 46.44 \\
\hline $\mathrm{Loss}_{2}$ in ignition & 9.6 \\
\hline
\end{tabular}

Table 4: Compressive strength

\begin{tabular}{|l|c|c|c|l|}
\hline $\mathbf{S} / \mathbf{N}$ & $\mathbf{X}_{\mathbf{1}}$ & $\mathbf{X}_{\mathbf{2}}$ & $\mathbf{X}_{\mathbf{3}}$ & Compressive strength $\left(\mathbf{K N} / \mathbf{m}^{2}\right)$ \\
\hline 1 & 4.05556 & 1.0000 & 0.111111 & 29.0652 \\
\hline 2 & 4.13793 & 0.9999 & 0.149425 & 26.4391 \\
\hline 3 & 4.18648 & 1.0000 & 0.165501 & 25.8480 \\
\hline 4 & 4.20588 & 0.9999 & 0.176471 & 25.6961 \\
\hline 5 & 4.22646 & 1.0000 & 0.180575 & 23.7042 \\
\hline 6 & 4.26829 & 0.9999 & 0.219512 & 23.5122 \\
\hline 7 & 4.27711 & 1.0000 & 0.204819 & 23.4500 \\
\hline 8 & 4.28395 & 1.0000 & 0.234568 & 21.6642 \\
\hline 9 & 4.28571 & 1.0000 & 0.242236 & 21.5578 \\
\hline 10 & 4.30303 & 0.9999 & 0.212121 & 21.0700 \\
\hline 11 & 4.31707 & 1.0000 & 0.219512 & 20.8198 \\
\hline 12 & 4.32653 & 1.0000 & 0.224490 & 20.7169 \\
\hline
\end{tabular}




\begin{tabular}{|l|l|l|l|l|}
\hline 13 & 4.35897 & 0.9999 & 0.282051 & 20.7169 \\
\hline 14 & 4.37500 & 1.0000 & 0.250000 & 20.6281 \\
\hline 15 & 4.43421 & 1.0000 & 0.315789 & 20.5600 \\
\hline 16 & 4.44325 & 0.9999 & 0.310693 & 19.6100 \\
\hline 17 & 4.45408 & 1.0000 & 0.275510 & 18.4059 \\
\hline 18 & 4.47815 & 1.0000 & 0.285347 & 17.9501 \\
\hline 19 & 4.48387 & 0.9999 & 0.290323 & 16.7242 \\
\hline 20 & 4.60000 & 1.0000 & 0.333333 & 15.0100 \\
\hline
\end{tabular}

\subsection{Analysis of Results}

The following terms cannot be estimated and were removed:

$\mathrm{X} 2 * \mathrm{X} 2$

Analysis of Variance

\begin{tabular}{|l|l|l|l|l|l|}
\hline Source & DF & Adj SS & Adj MS & F-Value & P-Value \\
\hline Model & 8 & 220.122 & 27.5153 & 67.93 & 0.000 \\
\hline Linear & 3 & 163.748 & 54.5827 & 134.76 & 0.000 \\
\hline X1 & 1 & 2.883 & 2.8826 & 7.12 & 0.022 \\
\hline X2 & 1 & 0.491 & 0.4905 & 1.21 & 0.295 \\
\hline X3 & 1 & 0.698 & 0.6981 & 1.72 & 0.216 \\
\hline Square & 2 & 3.885 & 1.9423 & 4.80 & 0.032 \\
\hline X1*X1 & 1 & 1.324 & 1.3245 & 3.27 & 0.098 \\
\hline X3*X3 & 1 & 0.657 & 0.6571 & 1.62 & 0.229 \\
\hline 2-Way Interaction & 3 & 2.765 & 0.9218 & 2.28 & 0.137 \\
\hline X1*X2 & 1 & 0.952 & 0.9523 & 2.35 & 0.153 \\
\hline X1*X3 & 1 & 1.037 & 1.0365 & 2.56 & 0.138 \\
\hline X2*X3 & 1 & 0.352 & 0.3517 & 0.87 & 0.371 \\
\hline Error & 11 & 4.455 & 0.4050 & - & - \\
\hline Total & 19 & 224.578 & - & - & - \\
\hline
\end{tabular}

Model Summary

\begin{tabular}{|l|c|l|l|}
\hline S & R-sq & R-sq(adj) & R-sq(pred) \\
\hline 0.636425 & $98.02 \%$ & $96.57 \%$ & $91.51 \%$ \\
\hline
\end{tabular}

Coded Coefficients

\begin{tabular}{|l|l|l|l|l|l|l|}
\hline Term & Effect & Coef SE & Coef & T-Value & P-Value & \multicolumn{1}{|l|}{ VIF } \\
\hline Constant & - & 20.944 & 0.311 & 67.25 & 0.000 & - \\
\hline $\mathrm{X} 1$ & -30.73 & -15.36 & 5.76 & -2.67 & 0.022 & 365.25 \\
\hline $\mathrm{X} 2$ & 0.474 & 0.237 & 0.215 & 1.10 & 0.295 & 2.09 \\
\hline $\mathrm{X} 3$ & 14.85 & 7.43 & 5.66 & 1.31 & 0.216 & 432.16 \\
\hline $\mathrm{X} 1 * \mathrm{X} 1$ & -64.6 & -32.3 & 17.9 & -1.81 & $0.098 \mathrm{c}$ & - \\
\hline $\mathrm{X} 3 * \mathrm{X} 3$ & -37.1 & -18.6 & 14.6 & -1.27 & 0.229 & 1031.74 \\
\hline $\mathrm{X} 1 * \mathrm{X} 2$ & 3.63 & 1.82 & 1.18 & 1.53 & 0.153 & 15.41 \\
\hline $\mathrm{X} 1 * \mathrm{X} 3$ & 103.5 & 51.8 & 32.4 & 1.60 & 0.138 & 4466.63 \\
\hline $\mathrm{X} 2 * \mathrm{X} 3$ & -1.90 & -0.95 & 1.02 & -0.93 & 0.371 & 14.52 \\
\hline
\end{tabular}


Regression Equation in Uncoded Units

$$
\begin{aligned}
Y & =528371-130074 X_{1}-534737 X_{2}+163925 X_{3}-436 X_{1}^{2}-1504 X_{2}^{2}+133415 X_{3}^{2} \\
& +1711 X_{1} X_{3}-170605 X_{2} X_{3}
\end{aligned}
$$

Equation 3 in the model equation for the prediction of the compressive strength of refractory bricks.
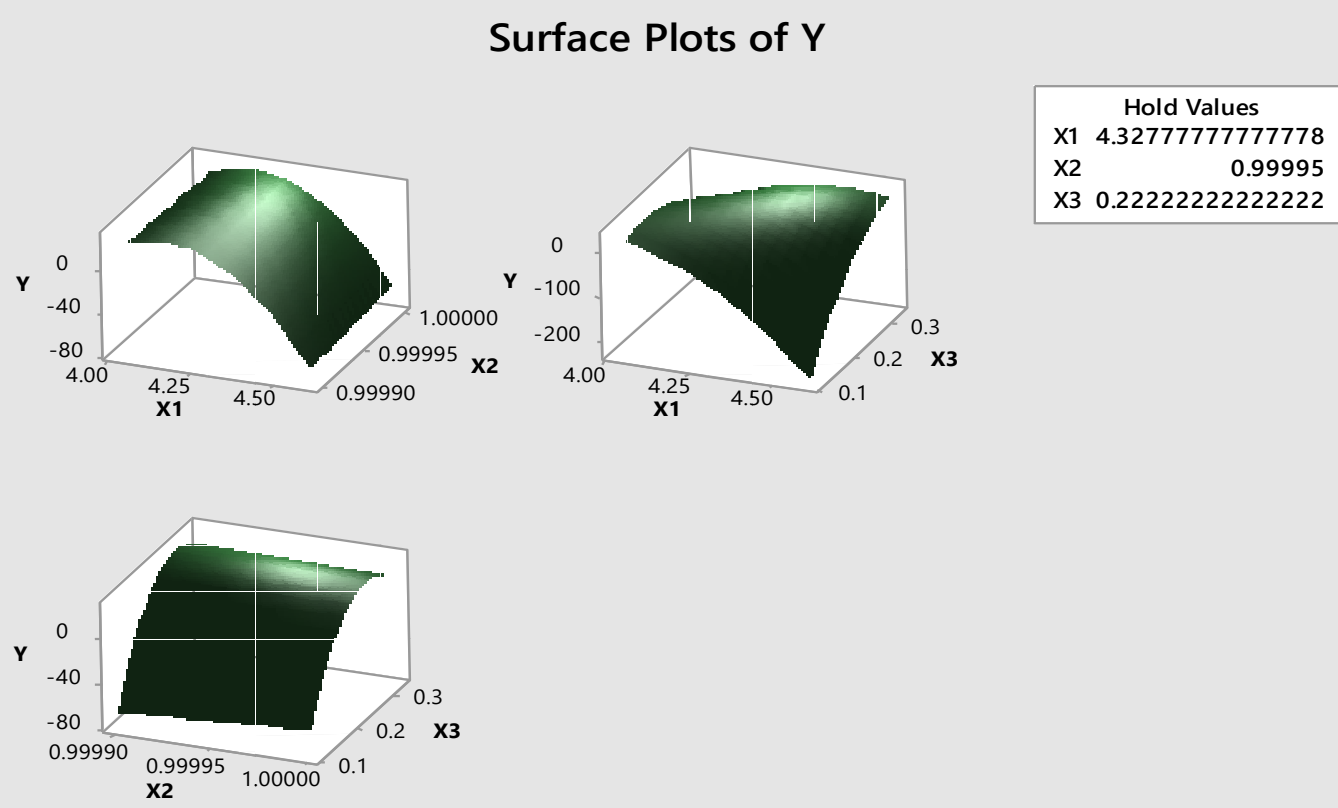

Figure 1: The interactions between the various mixes and the compressive strength

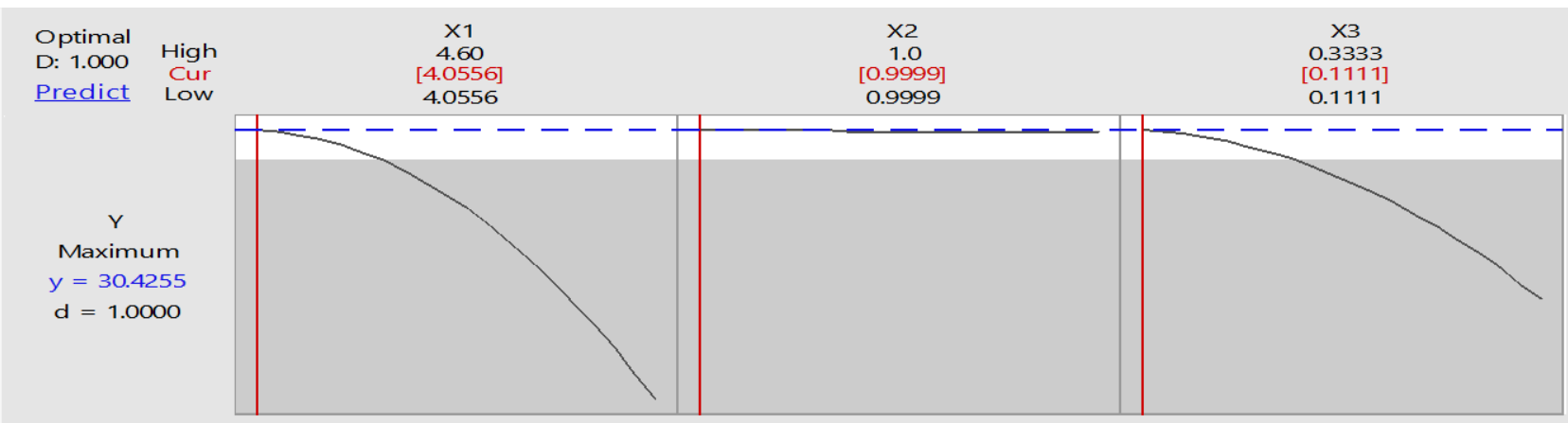

Figure 2: The maximum compressive strength $\left(30.4255 \mathrm{KN} / \mathrm{m}^{2}\right)$ at mix ration of 1.000:0.1111 and water/clay ratio of 4.0556 


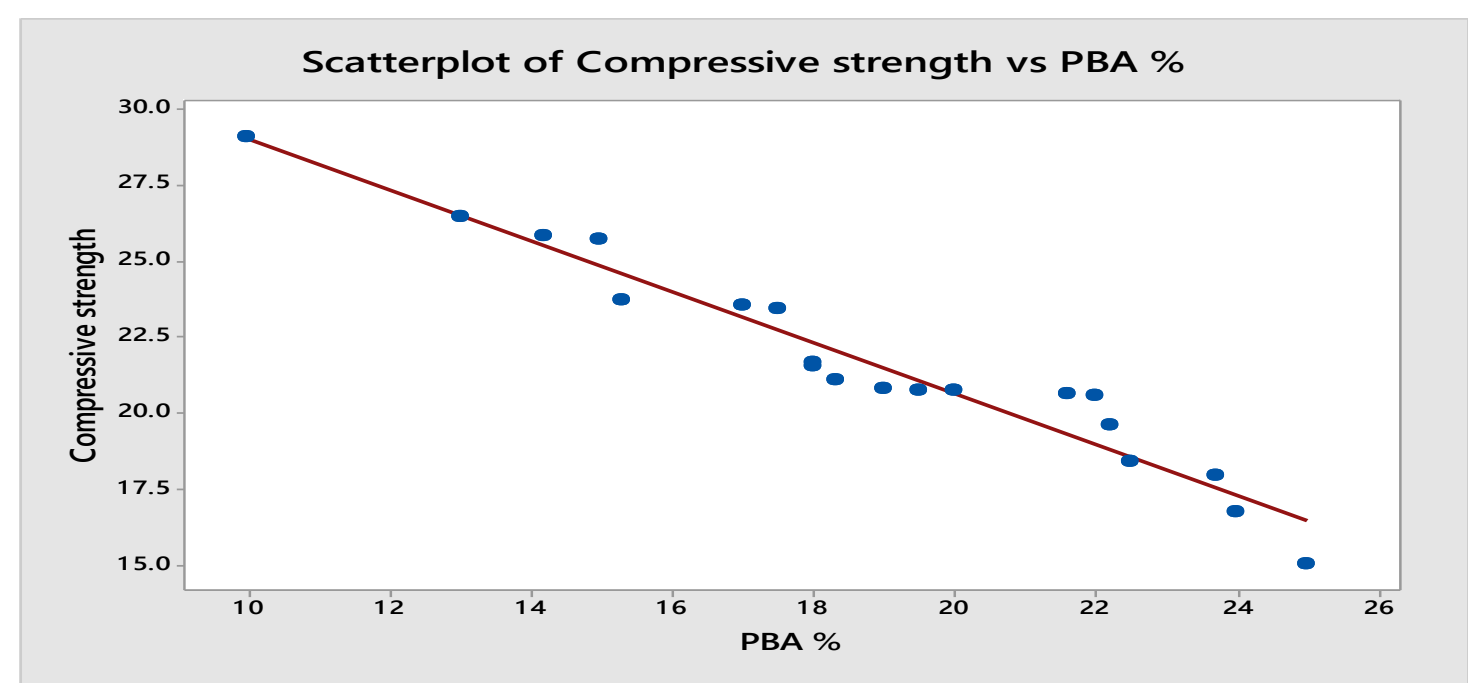

Figure 3: The graph of percentage of PBA against compressive strength

\subsection{Discussion of Results}

Twenty mixes were used based on the number generated by the software. From the results it can be seen that the addition of palm bunch ash to clay bricks reduces the compressive strength of the brick, this is because as more ash is added more pores are created which in turn reduces the compressive strength. The ash is added to the brick to enhance their properties. The interaction between the mixes and the compressive strength is as shown in fig 1.0. The figure shows all the interactions against the compressive strength. The figure shows the interaction that can give the maximum and the minimum compressive strength. The maximum compressive strength of strength $30.4255 \mathrm{KN} / \mathrm{m}^{2}$ at $\mathrm{mix}$ ration of $1.000: 0.1111$ and water/clay ratio of 4.0556 was achievable. The graph on figure 3 shows that as the percentage of palm bunch increases the lower the compressive strength of the refractory bricks produced. From the analysis of the results the Rsq value is $98.02 \%$ which means that the model can be use to predict responses from the various mixes, hence the model can be used to predict the compressive strength of refractory bricks. The Rsq(adj)) value is $96.57 \%$ which shows how well the model predicts new observations. The Rsq(pred) value is $91.51 \%$ which is okay.

\subsection{Conclusion}

The addition of palm bunch ash to bricks reduces the compressive strength of refractory brick. This is because as more ash is added to the brick more pores are created which in turn reduce the compressive strength of the refractory material. This pores are created when the ash are burnt off during the sintering process. The use of Surface Response Method reduces the rigorous mathematical analysis encountered in the formation of regression models. A regression model that can be used to predict the compressive strength of refractory bricks was developed based on the mixes produce. From this, refractory clay bricks with desired compressive strength can be produced locally and this will go a long way in discouraging the importation of refractory materials for our industries; hence reduce the stress on our local currency. This will also encourage the growth of our local industries. 


\section{References}

[1] Hassan M.A., Yami A.M., Raji A., and Ngala M. J. (2014); 'Effects of Sawdust and Rice Husk Additives on Properties of Local Refractory Clay', The International Journal of Engineering and Science (IJES), Volume 3, Issue 8, Pages 40-44.

[2] Elngar M. A.G., Mohamed F. M., El-Bohy S. A.H., Sharaby C. M., and Shalabi M. E. H. (2009); 'Factors Affected the Performance of Fire Clay Refractory Bricks', Górnictwo i Geoinżynieria, Rok 33, Zeszyt 4.

[3] Onwuka D.O., Chijioke C., Ibearugbulam O. H., Obilonu A. N, and Adinna B.O, (2014); 'Computer Program for the Determination of Optimum Compressive Strength of PBA - Clay Refractory Bricks', International Journal of Scientific and Research Publications, Volume 4, Issue 3.

[4] Malu, A. and Babson, A. (2007); 'Production Insulation Refractory Bricks with Kaolin and Saw Dust', Journal for Engineering and Applied Science, 2 (12), Pp 1697 - 199.

\footnotetext{
*Corresponding author.

E-mail address: cjuc2000@ gmail.com
} 